\title{
Polycrystalline Cubic Boron Nitride (PCBN) Tool Life and Wear in Turning of Amorphous-Crystalline Iron-Based Coatings
}

\author{
Ljubodrag Tanovic ${ }^{1}$ - Pavao Bojanic ${ }^{1},{ }^{*}-$ Radovan Puzovic $^{1}$ - Sergey Klimenko ${ }^{2}$ \\ 1University of Belgrade, Faculty of Mechanical Engineering, Serbia \\ ${ }^{2} \mathrm{~V}$. Bakul Institute for Superhard Materials of the National Academy of Sciences of Ukraine, Ukraine
}

The paper presents PCBN-Ciborit cutting tools life and wear test results. The effects of the machining regime when turning amorphous-crystalline $\mathrm{Fe}_{80} B_{20}$ and $\mathrm{Fe}_{79} \mathrm{Cr}_{16} \mathrm{~B}_{5}$ coating systems applied to conventional workpiece materials were assessed. It has been shown that the observed tool wear mechanisms are complex in their character and are dominated by abrasive-mechanical, adhesive and chemical effects in the cutting zone. Under changing turning conditions tool life is affected by the structural-phase composition and by the non-homogeneous structure of the coating. Specifically, when turning gas-flame coatings deposited with a $\mathrm{Fe}_{80} B_{20}$ electrode and electro-arc coatings with a $\mathrm{Fe}_{79} \mathrm{Cr}_{16} \mathrm{~B}_{5}$ electrode the lowest wear and the highest tool life was achieved at cutting speeds of $v=1.1$ to $1.2 \mathrm{~m} / \mathrm{s}$ and a back rake angle of $\gamma=-10^{\circ}$. It has been demonstrated that a change of the back rake angle from $\gamma=0$ to $-10^{\circ}$ does not have a great effect on tool life contrary to the case with $\gamma=-20^{\circ}$.

(C)2011 Journal of Mechanical Engineering. All rights reserved.

Keywords: cutting, tool wear, tool life, amorphous-crystalline coating

\section{INTRODUCTION}

Recently, materials possessing amorphous and amorphous-crystalline structures have been used to manufacture workpieces with improved physical-chemical and mechanical properties. Extraordinary enhancements in performance can be gained when, for surface layer reinforcement, amorphous alloys in the form of coatings are deposited on workpieces made of conventional design materials.

A relatively new trend is the manufacture of Fe-B, Fe-Si-B, Fe-Cr-B alloy coatings, which form amorphous structures. These coatings are relatively inexpensive and possess a uniform complex of properties, however, the quality of the machined surface frequently lacks desirable characteristics. The available technical literature discriminates between two directions of research in this area. The first deals with the different types of amorphous coatings and their application technologies, while the second deals with the tools for their machining.

Surfaces of the amorphous metal-metalloid alloy $\mathrm{Fe}_{80} \mathrm{~B}_{20}$ prepared by laser annealing were investigated [1] and [2]. Their results show that laser annealing leads to large enhancements in boron concentration in the first 0.5 to $1.0 \mathrm{~nm}$ of the surface, as a consequence of the surface oxidation of boron and iron. The supercooled liquid region, the tensile fracture strength and the Vickers hardness of the Fe-B-Zr amorphous alloys were measured [3] and [4]. The addition of $\mathrm{Nb}$ to the ternary $\mathrm{Fe}-\mathrm{B}-\mathrm{Zr}$ system was found to lead to significant changes in glass-forming ability (GFA), strength, and hardness. Their results are discussed in the context of the three empirical rules for the achievement of high GFA metallic glass and the change in packing density of the amorphous phases. A novel Gas Metal Arc Welding (GMAW) process, referred to as double-electrode GMAW or DE-GMAW, has been developed to make it possible to control melting at a desired level [5].

By means of differential scanning calorimeter (DSC) measurements, the thermal stability of an amorphous $\mathrm{Fe}_{80} \mathrm{~B}_{20}$ alloy after various periods of low-energy ball milling has also been studied [6] and [7]. The results indicate that the thermal stability of the amorphous 
$\mathrm{Fe}_{80} \mathrm{~B}_{20}$ ribbons can be enhanced upon mechanical deformation with a low milling intensity.

The second group of papers is related to PCBN tools and their use in hard turning. Many parameters, such as the composition and hardness of the workpiece and of the tool material, the environment and the machining parameters influence the different degradation mechanisms, which will eventually affect the workpiece surface finish and tool life [8] and [9]. Degradation mechanisms in PCBN tools are particularly dependent on the temperature and stress during cutting and on the chemical composition of both the tool and workpiece materials. According to [10], three main mechanisms are involved in the wear of PCBN tools: (1) chemical wear caused by the interaction with the environment (atmospheric oxidation and interaction with the workpiece), (2) formation of a protective layer on the surface of the tool at high temperatures, and (3) removal of this layer at very low temperatures or lower cutting speed, leading to abrasive wear and further chemical wear. The protective layer has also been considered [11].

Different classifications of tool wear in metal cutting can be found in the literature. In typical classifications the most prominent mechanisms of tool wear are abrasion, adhesion and diffusion. CBN tool flank wear is considered to be the main wear pattern and an important tool life metric in hard turning, and it has been extensively studied [12] to [15]. While flank wear is generally used as an indicator of tool wear, it does not tell the whole story. The brittle materials used for cutting tools, such as $\mathrm{CBN}$, require large wedge angles and negative rake angles. However, as crater wear progresses, the effective rake angle becomes more positive, leading to changes in the tool's cutting geometry [16] and [17].

The application of amorphous-crystalline coatings is limited to a considerable extent in practice due to the lack of scientifically based data on their mechanical machining properties. In the engineering literature not many works are available related to mechanical machining of coatings that possess an amorphous-crystalline structure. There is virtually no information about the effects of structure properties and amorphouscrystalline coatings on cutting tool life and wear. Coatings are considerably more difficult to machine by cutting as compared to monolithic materials of identical chemical composition and hardness due to the changing mechanical properties and machining allovance size as well as due to the presence of solid particles and pores in the structure.

The answer to the question about the effects of the coating material's non-homogeneity on tool life and wear is crucial in the choice of machining regime parameters. A substantial improvement in techno-economic parameters of the cutting process in coated components can be achieved by using tools made of super-hard materials such as PCBN. Therefore, the principal aim of this paper is to experimentally assess the influence of key machining partameters on PCBN tool life and wear.

\section{EXPERIMENTAL SETUP AND PROCEDURES}

The experiments were carried out using a $\mathrm{PH}$ 42-CNC lathe with a $16 \mathrm{~kW}$ spindle with a speed range from 16 to $5200 \mathrm{rpm}$, with PCBNCiborit cutter bits (Institute of superhard materials, Kiev, UA), a scanning electron microscope (JSPM 5200), and workpiece coatings with the following structures: $\mathrm{Fe}_{80} \mathrm{~B}_{20}$ and $\mathrm{Fe}_{79} \mathrm{Cr}_{16} \mathrm{~B}_{5}$ formed by various technologies (Fig. 1). The base workpiece material on which the coatings were deposited was steel 40Ch-GOST (1040 SAE).

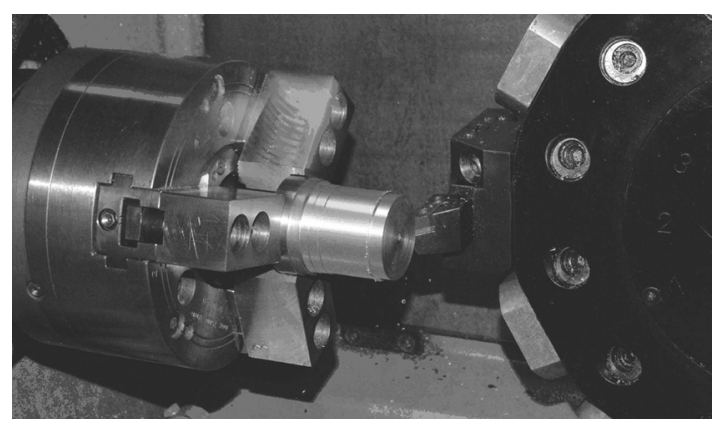

Fig. 1. Experimental set-up

Table 1 lists the mechanical characteristics of the coating materials while Table 2 gives the hardness values of the coatings. The tests were performed under the following conditions: cutting speed 0.6 to $2.7 \mathrm{~m} / \mathrm{s}$; feed 0.05 to $0.18 \mathrm{~mm} / \mathrm{rev}$; cutting tool, insert PCBN-Ciborit, RNMN 0703-T, back rake angle 0 to $-20^{\circ}$. 
Table 1. Mechanical characteristics of the coating materials

\begin{tabular}{|c|c|c|c|c|c|}
\hline Material & Vickers hardness, $H V[\mathrm{GPa}]$ & Stress fracture $s[\mathrm{GPa}]$ & Young's Modul $E[\mathrm{GPa}]$ & $\sigma / E$ & $H V / \sigma$ \\
\hline $\mathrm{Fe}_{80} \mathrm{~B}_{20}$ & 10.8 & 3.5 & 170 & 0.02 & 3.1 \\
\hline $\mathrm{Fe}_{79} \mathrm{Cr}_{16} \mathrm{~B}_{5}$ & 10.3 & 3.06 & - & - & 3.3 \\
\hline
\end{tabular}

Table 2. Hardness values of the coatings deposited by different methods

\begin{tabular}{|c|c|}
\hline Coatings & Hardness, HRc \\
\hline $\begin{array}{l}\text { Gas-flame coating with } \\
\mathrm{Fe}_{80} \mathrm{~B}_{20} \text { electrode }\end{array}$ & 56 to 58 \\
\hline $\begin{array}{l}\text { Gas-flame coating with } \\
\mathrm{Fe}_{80} \mathrm{~B}_{20} \text { powder }\end{array}$ & 52 to 56 \\
\hline $\begin{array}{l}\text { Electro-arc coating with } \\
\mathrm{Fe}_{80} \mathrm{~B}_{20} \text { electrode }\end{array}$ & 56 to 58 \\
\hline $\begin{array}{l}\text { Gas-flame coating with } \\
\mathrm{Fe}_{79} \mathrm{Cr}_{16} \mathrm{~B}_{5} \text { powder }\end{array}$ & 54 to 58 \\
\hline $\begin{array}{l}\text { Electro-arc coating with } \\
\mathrm{Fe}_{79} \mathrm{Cr}_{16} \mathrm{~B}_{5} \text { electrode }\end{array}$ & 56 to 58 \\
\hline
\end{tabular}

\section{TOOL WEAR AND TOOL LIFE RESULTS}

The turning of workpieces with amorphouscrystalline coatings $\mathrm{Fe}_{80} \mathrm{~B}_{20}$ and $\mathrm{Fe}_{79} \mathrm{Cr}_{16} \mathrm{~B}_{5}$ with PCBN tools was performed at relatively high cutting speeds, lower feeds and depths of cut due to constraints imposed by the coating thickness of $a=0.1$ to $0.6 \mathrm{~mm}$. As the depth of cut was small, the contact area between the tool and the chip was also small, resulting in a very high specific load in the contact area. The experiments were replicated five times under identical machining conditions. Tool flank wear was measured and the mean measured value was taken for the result, with deviations of up to $5 \%$. For every coating and corresponding cutting regime a new Ciborit cutter bit was used. The investigations were based on observations and measurements of flank wear (VB) in turning of the corresponding coatings and the determination of the tool's life. Fig. 2 shows a photograph of the back rake and the flank surface wear patterns of the Ciborit cutting tools, while Fig. 3 presents the nature of the changes in tool flank wear when turning $\mathrm{Fe}_{80} \mathrm{~B}_{20}$ and $\mathrm{Fe}_{79} \mathrm{Cr}_{16} \mathrm{~B}_{5}$ coatings. In Fig. 3 the curves 1, 2 represent the curve of $\mathrm{Fe}_{80} \mathrm{~B}_{20}$ coating wear, while the curves 3 and 4 represent the curve of $\mathrm{Fe}_{79} \mathrm{Cr}_{16} B_{5}$ coating wear. Due to a large range of values along the $\mathrm{T}$ axis, the wear curves are represented in two segments such as: the initial segments of the curves on the $\mathrm{T}$ axis are denoted with $\mathrm{T}_{2,4}$, while the continuation of the wear curves is denoted with $\mathrm{T}_{1,3}$.

Experimental tool life data when machining two types of coatings formed by various technologies, assuming a $V B=0.25 \mathrm{~mm}$ tool wear criterion, are shown in Fig. 4. Investigations on the effects of the cutting regime and of the tool's back rake angle on tool life were conducted on $\mathrm{Fe}_{80} \mathrm{~B}_{20}$ based coatings and the results obtained are presented in Fig. 5 and in the 3D coordinate system in Fig. 6.
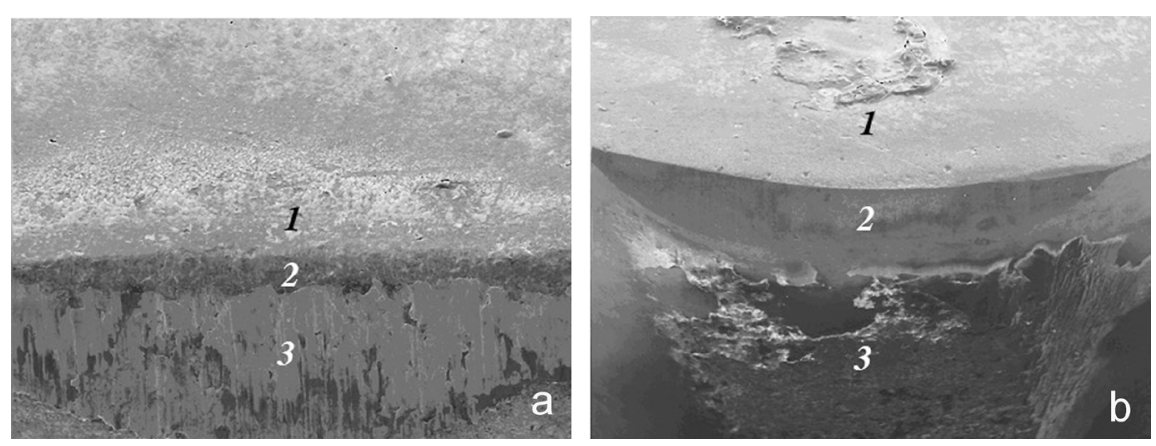

Fig. 2. PCBN-Ciborit wear (1-back rake surface; 2-cutting edge; 3-flank; $f=0.05 \mathrm{~mm} / \mathrm{rev} ; a=0.2 \mathrm{~mm}$; $\gamma=-10^{\circ}$ ) when machining of coatings; a) gas flame with electrode $\mathrm{Fe}_{80} \mathrm{~B}_{20}, \mathrm{v}=1.7 \mathrm{~m} / \mathrm{s}, \times 150$; b) electro arc with electrode $\mathrm{Fe}_{79} \mathrm{Cr}_{16} B_{5}, v=2.7 \mathrm{~m} / \mathrm{s}, \times 150$ ) 


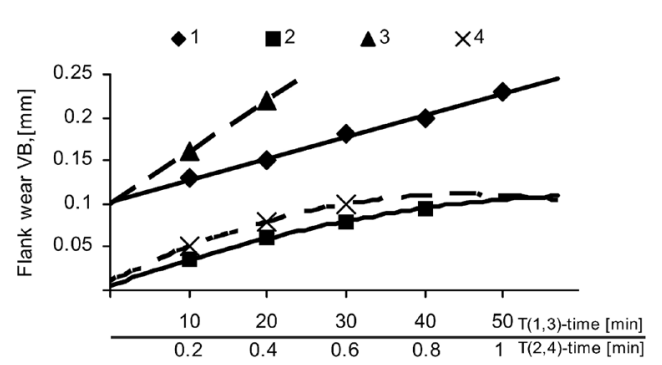

Fig. 3. Change in flank wear VB during cutting (1, 2: gas flame coating with electrode $\mathrm{Fe}_{80} B_{20}$;

3, 4: electro arc coating with electrode $\left.\mathrm{Fe}_{79} \mathrm{Cr}_{16} B_{5}\right): v=2.7 \mathrm{~m} / \mathrm{s}, f=0.05 \mathrm{~mm} / \mathrm{rev}$; $A=0.2 \mathrm{~mm} ; \gamma=-10^{\circ}$

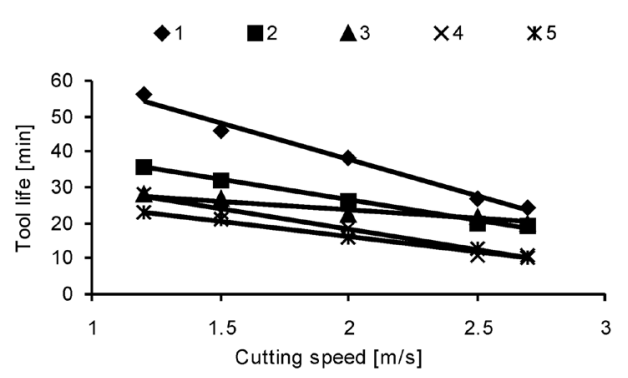

Fig. 4. Change in tool life $(V B=0.25 \mathrm{~mm})$ as a function of cutting speed $(f=0.05 \mathrm{~mm} / \mathrm{rev}, \alpha$ $\left.=0.2 \mathrm{~mm}, \gamma=-10^{\circ}\right): 1:$ gas flame coating with electrode $\mathrm{Fe}_{80} \mathrm{~B}_{20}$, 2: electro arc coating with electrode $\mathrm{Fe}_{80} B_{20}$, 3: gas flame coating with powder $\mathrm{Fe}_{80} \mathrm{~B}_{20}$, 4: electro arc coating with electrode $\mathrm{Fe}_{79} \mathrm{Cr}_{16} \mathrm{~B}_{5}$, 5: gas flame coating with powder $\mathrm{Fe}_{79} \mathrm{Cr}_{16} \mathrm{~B}_{5}$

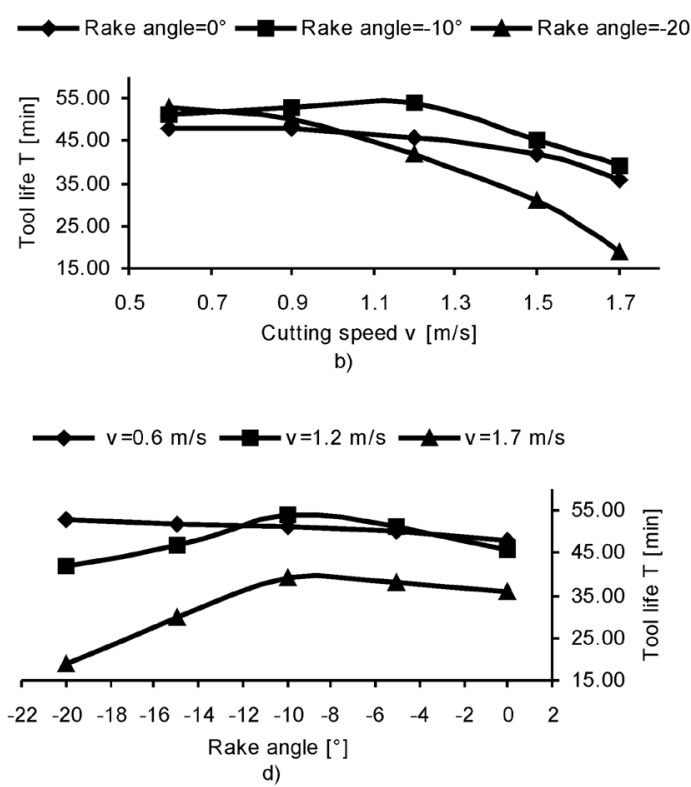

Fig. 5. Change in tool life $(V B=0.25 \mathrm{~mm})$ in turning of gas flame coatings with electrode $\mathrm{Fe}_{80} \mathrm{~B}_{20}$ as a the function of: $a$ and c) cutting speed and feed $\left(a=0.1 \mathrm{~mm}, \gamma=-10^{\circ}\right), b$ and $\left.d\right)$ cutting speed and back rake angle $(f=0.05 \mathrm{~mm} / \mathrm{rev}, a=0.2 \mathrm{~mm})$

\section{DISCUSSION}

When turning of coatings whose structure is over $70 \%$ amorphous $\left(\mathrm{Fe}_{80} \mathrm{~B}_{20}\right)$ a continuous/ ribbon chip is being formed. This chip is contact with tool back rake surface over a long period of time, resulting in tool wear across the back rake surface as depicted in Fig. 2a. Due to the low thickness of the chips, the tool contact surface approaches the cutting edge and results in its rapid wear and destruction. When turning coatings whose amorphous structure accounts for $50 \%$ (arc coatings formed with electrodes $\mathrm{Fe}_{79} \mathrm{Cr}_{16} \mathrm{~B}_{5}$ ) the tool predominantly wears across the flank (Fig. $2 b)$. This is the consequence of the fact that the structure of these coatings is formed of separate 

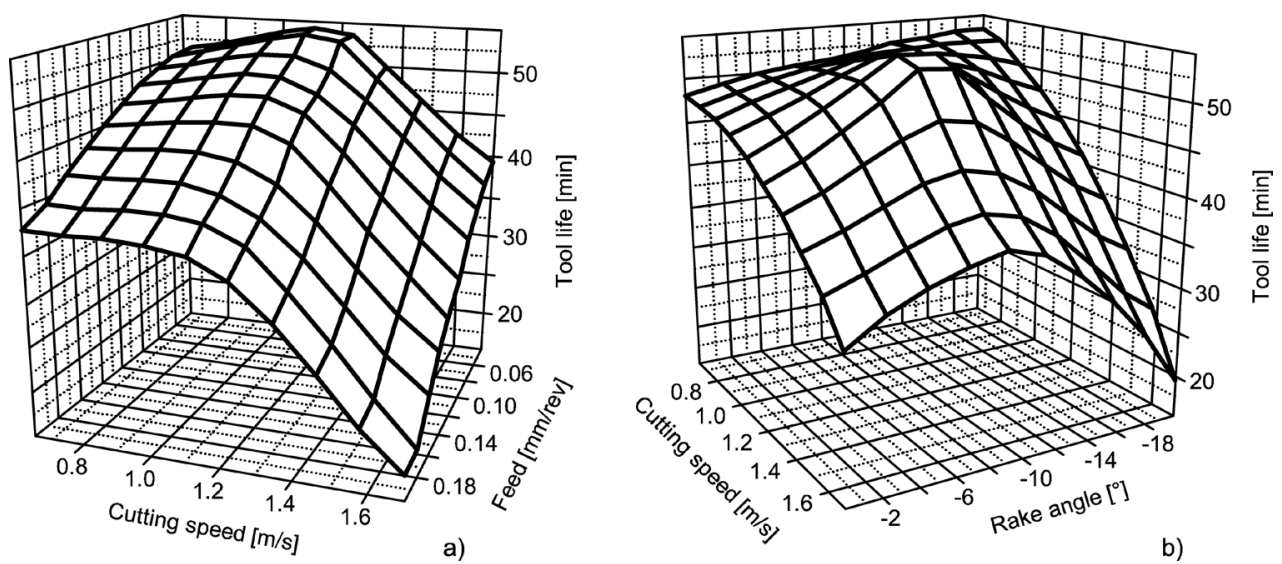

Fig. 6. Change in tool life in the $3 D$ coordinate system $T, v, f$ and $T, v, \gamma$, (machining conditions, Fig. 5)

fragments which are, unlike highly amorphous coatings, insufficiently deformed in the layering process and weakly inter-connected, primarily due to diffusion processes and mechanical interaction. In machining of both types of coatings initial tool wear is observed, which then turns into uniform wear, as noticeable in Fig. 3.

Simultaneously with tool back rake and flank surface wear, when turning the respective coatings, the occurrence of deposits was observed on the tool's back rake surface. Based on the tests performed, it was observed that when turning coatings of identical chemical composition but formed by different technologies deposits with various characteristics occur on tool back rake surface. Namely, after turning of electro arc coating $\mathrm{Fe}_{79} \mathrm{Cr}_{16} \mathrm{~B}_{5}$ deposits of relatively high density are formed on the tool's working surfaces, while when turning of heterogeneous gas flame coatings of the same chemical composition loose unstable deposits are observable and are periodically removed in the machining process leading to more intensive wear and lower tool life. Different deposit forms and structures are created during machining of coatings of the same chemical composition, but formed by different technologies, indicating that the characteristics of the contact inteactions in the cutting zone are different and determined by the specific method by which each coating was formed.

It is well-known that coatings on workpieces are of relatively low thickness but high price, therefore tool life determination is very costly and, in some cases, tests are difficult to carry out. Hence, when determining tool life, it is assumed that [18] if in the process of machining tool wear intensity under machining conditions $(v, f, \gamma)$ is higher or lower compared to tool wear intensity under a different set of machining conditions $\left(v^{\prime}, f^{\prime}, \gamma^{\prime}\right)$, then the trend in the changes will be retained along the entire tool wear curve. This makes it possible to conduct tests to find out a sharp tool's life in turning of various types of coatings, where $V B=0.1 \mathrm{~mm}$ is taken as the tool life criterion (T0.1).

Experimental data presented in Fig. 3 indicate that tool life relationships can be established for a $V B=0.25 \mathrm{~mm}$ wear $\left(\mathrm{T}_{0.25}\right)$ value relative to the tool life for a $V B=0.1 \mathrm{~mm}$ wear. Namely, when turning gas flame coatings with electrode $\mathrm{Fe}_{80} \mathrm{~B}_{20}$ for $V B=0.1 \mathrm{~mm}$, the tool life is $\mathrm{T}_{0.1}=0.88 \mathrm{~min}$. The continuation of the machining process until $V B=0.25 \mathrm{~mm}$ is reached results in a tool life of $\mathrm{T}_{0.25}=57 \mathrm{~min}$. According to the above, tool life relationships for machining of coatings can be established. Specifically, for the cases considerd here:

a) gas-flame coating formed with an electrode

$$
\mathrm{Fe}_{\mathbf{8 0}} \mathrm{B}_{\mathbf{2 0}} \rightarrow \mathrm{T}_{\mathbf{0 . 2 5}}=64.7 \mathrm{~T}_{\mathbf{0 . 1}},
$$

b) electro-arc coating formed with an electrode

$$
\mathrm{Fe}_{79} \mathrm{Cr}_{16} \mathrm{~B}_{5} \rightarrow \mathrm{T}_{\mathbf{0 . 2 5}}=45 \mathrm{~T}_{\mathbf{0 . 1}} \text {. }
$$

It was observed that on the tool's working surfaces after turning of electric-arc deposited coatings, $\mathrm{Fe}_{79} \mathrm{Cr}_{16} \mathrm{~B}_{5}$ deposits of relatively higher density were formed, while when turning heterogeneous gas-flame coatings of the same chemical composition loose unstable deposits were created. The latter deposits were periodically 
removed during the machining process, leading to more intensive tool wear and decrease in tool life.

Based on the results for tool life measurements under different machining conditions of the respective coatings, tool life measures were established, as presented in Fig. 4.

A general look of the deposits and their position relative to the tool's cutting edges changes, depending on machining conditions. When it comes to machining of $\mathrm{Fe}_{80} \mathrm{~B}_{20}$ based coatings, the maximal tool life is achieved during machining of the gas-flame deposited coating with electrodes, while minimal life was achieved with powder coating. It should be pointed out that a lower influence of coating heterogeneity on tool life is observed with an increase in cutting speed. Thus, cutting edge life in turning at a cutting speed of $v=2 \mathrm{~m} / \mathrm{s}(f=0.05 \mathrm{~mm} / \mathrm{rev}, a=0.2$ $\mathrm{mm}$ ) of the arc coating $\mathrm{Fe}_{79} \mathrm{Cr}_{16} \mathrm{~B}_{5}$ amounts to 18 minutes, while that of the gas coating $\mathrm{Fe}_{79} \mathrm{Cr}_{16} \mathrm{~B}_{5}$ is 16 minutes. However, when the cutting speed is reduced to $v=1.2 \mathrm{~m} / \mathrm{s}$ under analogous conditions the tool life is at the 27 and 23 minutes level at the $V B=0.25 \mathrm{~mm}$ benchmark for wear. The cutting speed shows a great influence on the contact conditions and on the physical characteristics of the phenomena that accompany tool wear.

Cutting speed largely affects tool wear, and maximal tool life is achieved at a cutting speed of $v=1.1$ to $1.2 \mathrm{~m} / \mathrm{s}$.

Under this machining regime, contact conditions are created for which the intensity of the abrasive interaction in the cutting zone is significantly decreased and the tool is subjected to optimal dynamic stresses, adhesion contact and chemical interactions. All the aforementioned conditions lead to a minimum intensity of wear. With an increase in the cutting speed, tool life gradually decreases as a consequence of the elevated intensity of wear and changes in both the temperature and dynamic conditions of cutting, as well as of the development of highly unfavorable impact loads on the Ciborit cutter bit.

The influence of feed is essentially coupled with that of the cutting speed. It is characteristic of the investigated cutting speed range that tool life decreases with an increase in the feed. In turning at speed of $v>1.2 \mathrm{~m} / \mathrm{s}$ the feed influences tool life more significantly than at lower cutting speeds. Namely, an increase in the feed leads to a temperature rise in the cutting zone leading to considerably intensified chemical reactions that, in turn, lead to a decrease in tool life. In turning of the coatings being considered in the present work, the tool back rake angle also appreciably influences tool life. Thus, a change in $\gamma=0$ to $-10^{\circ}$ does not show a high influence on tool life change at cutting speeds up to $v=1.2 \mathrm{~m} / \mathrm{s}$, which is not the case when $\gamma=-20^{\circ}$ (Figs. 5a and c, 6). This is explained by the increase in the chip and tool back rake contact surface area. So, an optimum value for the back rake is $\gamma=-10^{\circ}$, because at this value the tool possesses the highest tool life, which is needed to achieve the lowest values of the machined surface's roughness parameters.

\section{CONCLUSION}

The paper presents tests results for PCBN Ciborit tool wear and the determination of its tool life when turning coatings that possess a heterogeneous amorphous-crystalline structure and that are formed by various technologies.

On the basis of what has been said, the mechanism of PCBN cutting edge wear in turning of amorphous-crystalline coatings is complex in its characteristics and is influenced by abrasive, mechanical, adhesive and chemical interactions in the cutting zone. The wear characteristics are dependent upon the structure of the machined material, cutting regime and tool geometry.

The investigations carried out in turning of gas-flame coatings $\mathrm{Fe}_{80} \mathrm{~B}_{20}$ with Ciborit tools show that the highest tool life was achieved at a cutting speed of $1.2 \mathrm{~m} / \mathrm{s}$, feed $0.06 \mathrm{~mm} / \mathrm{rev}$ and rake angle $\gamma=-10^{\circ}$ (Fig. 5).

The results indicate that in the tested cutting speed range, an increase in the feed leads to a tool life decrease. In turning at $v>1.2 \mathrm{~m} / \mathrm{s}$, the influence of the feed on tool life decrease is greater than at lower cutting speeds. It has been demonstrated that a change in the back rake angle $\gamma=-10$ to $-20^{\circ}$ at the applied cutting speeds and feed leads to tool life decrease, and that as a consequence of tool wear increase. It should be pointed out that as the cutting speed is increased the influence of heterogeneity of the coatings $\mathrm{Fe}_{80} \mathrm{~B}_{20}$ and $\mathrm{Fe}_{79} \mathrm{Cr}_{16} \mathrm{~B}_{5}$ on tool life is decreased, as indicated by Fig. 3 . 


\section{REFERENCES}

[1] Gimzewski, J.K., Moller, R., Myhra, S., Schlittler, R.R., Stoll, E. (1990). Investigations of the surface of the amorphous alloy $\mathrm{Fe}_{80} \mathrm{~B}_{20}$ by STM, XPS and AES. Journal of Non-Crystalline Solids, vol. 116, p. 253261, DOI:10.1016/0022-3093(90)90699-M.

[2] Fan, G.J., Quan, M.X., Hu. Z.Q. (1996). Deformation enhanced thermal stability of an amorphous $\mathrm{Fe}_{80} \mathrm{~B}_{20}$ alloy. Journal of Applied Physics, vol. 80, no. 10, p. 6055-6057, DOI:10.1063/1.363563.

[3] Ma, L., Wang, L., Zhang, T., Inoue, A. (1999). Effect of $\mathrm{Nb}$ addition on glass-forming ability, strength, and hardness off Fe-B-Zr amorphous alloys. Materials Research Bulletin, vol. 34, no. 6, p. 915-920, DOI:10.1016/S00255408(99)00089-6.

[4] Hirata, A., Hirotsu, Y., Amiya, K., Nishiyama, N., Inoue, A. (2008). Nanocrystallization of complex FeB-type structure in glassy $\mathrm{Fe}-\mathrm{Co}-\mathrm{B}-\mathrm{Si}-\mathrm{Nb}$ alloy. Intermetallics, vol. 16, no. 4, p. 491-497, DOI:10.1016/j. intermet.2007.11.006.

[5] Li, K., Zhang, Y. (2007). Metal transfer in double-electrode gas metal arc welding. ASME, Journal of Manufacturing Science and Engineering, vol. 129, no. 6, p. 9911000, DOI:10.1115/1.2769729.

[6] Fan, G.J., Quan, M.X., Hu, Z.Q. (2008). Deformation-enhanced thermal stability of an amorphous $\mathrm{Fe}_{80} \mathrm{~B}_{20}$ alloy. Intermetallics, vol. 16, no. 4, p. 491-497.

[7] Alaeddine, M., Ando, T.R., Doumanidis, C.C. (2005). Modeling the melting and dissolution stages during thermal processing of intermetallic coatings from layered precursors. ASME, Journal of Manufacturing Science and Engineering, vol. 127, p. 148156.

[8] Angseryd, J., Coronel, E., Elfwing, M., Olsson, E., Andren, H.O. (2009). The microstructure of the affected zone of a worn PCBN cutting tool characterised with SEM and TEM. Wear, vol. 267, no. 5-8, p. 10311040, DOI:10.1016/j.wear.2008.12.075.

[9] Velkavrh, I., Kalin, M., Vižintin, J. (2008). The performance and mechanisms of DLCcoated surface in contact with steel in boundary-lubrication conditions - a review. Strojniški vestnik - Journal of Mechanical Engineering, vol. 51, no. 6, p. 304-329.

[10] Chou, K., Evans, Y., Barash, C.J. (2002). Experimental investigation on CBN turning of hardened AISI 52100 steel. Journal of Materials Processing Technology, vol. 124 , p. 274-283, DOI:10.1016/S09240136(02)00180-2.

[11] Klimenko, S.A., Mukovoz, Yu.A., Lyashko, V.A., Vashchenko, A.N., Ogorodnik, V.V. (1992). On the wear mechanism of cubic boron Nitride base cutting tools. Wear, vol. 157 , no. 1 , p. 1-7, DOI:10.1016/00431648(92)90183-9.

[12] Poulachon, G., Moisan, A., Jawahir, I.S. (2001). Tool-wear mechanisms in hard turning with polycrystalline cubic boron nitride tools. Wear, vol. 250, p. 576-586, DOI:10.1016/S0043-1648(01)00609-3.

[13] Poulachon, G., Bandyopadhyay, B.P., Jawahir, I.S., Pheulpin, S., Seguin, E. (2004). Wear behavior of CBN tools while turning various hardened steels. Wear, vol. 256, no. 3-4, p. 302-310, DOI:10.1016/S00431648(03)00414-9.

[14] Barry, J., Byrne, G. (2001). Cutting tool-wear in the machining of hardened steels. Wear, vol. 247 , p. 152-160, DOI:10.1016/S00431648(00)00531-7.

[15]Huang, Y., Liang, S.Y. (2004). Modeling of CBN tool flank wear progression in finish hard turning. ASME Journal of Manufacturing Science and Engineering, vol. 126, no. 1, p. 98-106, DOI:10.1115/1.1644543.

[16]Huang, Y., Liang, S.Y. (2004). Modeling of CBN tool crater wear in finish hard turning. International Journal of Advanced Manufacturing Technology, vol. 24, no. 9-10, p. 632-639, DOI:10.1007/s00170-003-17445.

[17]Huang, Y., Dawson, Ty.G. (2005). Tool crater wear depth modeling in CBN hard turning. Wear, vol. 258 , no. 9 , p. 1455-1461, DOI:10.1016/j.wear.2004.08.010.

[18] Ber, A., Kaldor, S. (1982). The first seconds off cutting. Annals of the CIRP, vol. 31, no. $1, \quad$ p. $13-17$, DOI:10.1016/S00078506(07)63260-0. 